\title{
ABORDAGENS POLÍTICAS NA GEOGRAFIA AGRÁRIA: Tendências metodológicas e a interdisciplinaridade pós 1990
}

POLITICAL APPROACHES IN AGRARIAN GEOGRAPHY: Methodological trends and interdisciplinarity post 1990

\section{APPROACHES POLITIQUES DANS LA GEOGRAPHIE AGRAIRE: Tendances méthologogiques et interdisciplinarité après 1990}

\author{
Flamarion Dutra Alves \\ Doutor em Geografia pela UNESP - Rio Claro \\ Prof. Adjunto da Universidade Federal de Alfenas \\ Endereço: Universidade Federal de Alfenas - Instituto de Ciências da Natureza \\ Curso de Geografia - Prédio V - Sala V 306H \\ Rua Gabriel Monteiro da Silva, 700. Centro - Alfenas/MG. CEP: 37130-000 \\ E-mail: dutrasm@yahoo.com.br
}

\begin{abstract}
Resumo
Este artigo propõe-se em verificar a produção em geografia agrária no Brasil, pós 1990, salientando os estudos de caráter político e as tendências teórico-metodológicas. A base consultada foram nove periódicos científicos em geografia entre os anos de 1991 a 2009. Destacam-se o aumento de estudos com abordagem política e a multiplicidade de concepções metodológicas nas pesquisas em geografia agrária neste início de século XXI, comprovando a necessidade de estudos interdisciplinares que não se atrelam a um único enfoque.
\end{abstract}

Palavras-chave: história do pensamento geográfico, metodologia, epistemologia, teoria e método.

\begin{abstract}
This essay aims at verifying the production in Agrarian Geography in Brazil, after 1990, which highlights the studies of political characteristics and the theoretical methodological trends. The sources consulted were nine scientific journals of Geography between the years 1991 and 2009. It is remarkable the raise in those studies which use political approaches and the multiplicity of methodological concepts in the researches in the Agrarian Geography in the early $21^{\text {st }}$ century, which proves the need of interdisciplinary studies, which are not centered in an unique focus.

Key-Words: History of Geographic Thought, Methodology, Epistemology, Theory and Method.
\end{abstract}




\section{Résumé}

Cet article propose de verifier la production dans la géographie agraire au Brésil, après 1990, tout en remarquant les études de caractère politique et les tendances théoriqueméthodologiques. Les sources consultées ont été neuf revues scientifiques en géographie entre les années de 1991 et 2009. Il est remarquable l'augmentation des etudes avec des approaches politiques et la multiplicité de conceptions methodologiques aux recherches en géographie agraire dans le commencement du XXIème siècle, en démontrant le besoin des études interdisciplinaires qui ne s'attachent pas à un seul focus.

Mots-Clés: Histoire de la pensée géographique, méthologie, epistemologie, théorie et méthode.

\section{Introdução}

Este estudo acerca da história da geografia agrária brasileira tem o propósito de delinear algumas considerações da geografia contemporânea, analisando a produção bibliográfica em periódicos científicos selecionados, no que tange a geografia agrária e especificamente os enfoques teórico-metodológicos embasadores das abordagens empregadas nas pesquisas.

Centraremos as análises metodológicas no período recente que compreende os últimos vinte anos (1990 - 2009), em especial a abordagem política, sendo um momento de afirmações, renovações e projeções dos referenciais metodológicos na geografia.

O período pós 1980 na geografia brasileira é comumente denominado como "Crítico" ou "Social" ou "Marxista" na maioria das pesquisas realizadas, considerado um paradigma na história da geografia. Entretanto, os estudos realizados por Alves (2010) mostram que a geografia agrária brasileira pós 1990 apresentou uma diversidade de matrizes teórico-metodológicas, que na prática não concretizou esse paradigma marxista, como foi à geografia regional clássica ou a geografia teorética quantitativa, apresentando uma tendência plural com vários enfoques metodológicos, conforme aponta Roberto Lobato Corrêa quando diz que "O movimento crítico na geografia brasileira, iniciado em 1978, perdeu o fôlego na década de 1990” (2010, p.65).

Dessa maneira, analisaremos as diversas formas que foram conduzidas as pesquisas em geografia agrária no Brasil tecendo considerações sobre a abordagem política na metodologia da pesquisa. 


\section{Metodologia}

Este artigo compreende uma parte da pesquisa desenvolvida por Alves (2010), no qual compilou os artigos referentes à geografia agrária em dez periódicos científicos na área da geografia, desde 1939 com a Revista Brasileira de Geografia. Entretanto, o período em questão neste artigo, 1990 a 2010, compreende nove revistas que foram base para o levantamento desta pesquisa: Revista Brasileira de Geografia (1991-2005), Boletim de Geografia Teorética (1991-1994), Geousp (1997-2009), Boletim Goiano de Geografia (1991-2009), Boletim Paulista de Geografia (1991-2009), Geografia - Rio Claro (1991-2009), Sociedade \& Natureza (1991-2009), Geosul (1991-2009) e Terra Livre (1991-2009).

O total de artigos com abordagem política nas duas décadas em análise totalizou 40 trabalhos, sendo 15 na década de 1990 e 25 na primeira década do século XXI (Quadro 1). A interpretação estes artigos levou em consideração, as palavraschaves e as expressões teórico-metodológicas, a fim de demonstrar uma análise de conteúdo - quantitativa, além de verificar o conteúdo, escalas de análise e discussão entendendo a análise de discurso.

Quadro 1 - Artigos consultados nos periódicos em geografia entre 1991 - 2009.

\begin{tabular}{|c|c|c|c|}
\hline ANO & AUTOR (ES) & TÍTULO DO ARTIGO & REVISTA \\
\hline 1991 & KOHLHEPP, Gerd. & $\begin{array}{l}\text { Mudanças estruturais na agropecuária e mobilidade da } \\
\text { produção rural no norte do Paraná - Brasil. }\end{array}$ & $\begin{array}{l}\text { Rev.Brasileira } \\
\text { de Geografia }\end{array}$ \\
\hline 1991 & BRITO, Maria Socorro. & $\begin{array}{l}\text { O Programa Nacional de Irrigação: uma avaliação } \\
\text { prévia dos resultados. }\end{array}$ & $\begin{array}{l}\text { Rev.Brasileira } \\
\text { de Geografia }\end{array}$ \\
\hline 1992 & MACHADO, Lia. & A fronteira agrícola na Amazônia brasileira. & $\begin{array}{l}\text { Rev.Brasileira } \\
\text { de Geografia }\end{array}$ \\
\hline 1992 & $\begin{array}{l}\text { VARGAS, Maria } \\
\text { Augusta Mundin }\end{array}$ & $\begin{array}{l}\text { A natureza sertaneja das políticas de desenvolvimento: } \\
\text { sertão sergipano do São Francisco. }\end{array}$ & $\begin{array}{l}\text { Bol. Paulista } \\
\text { de Geografia }\end{array}$ \\
\hline 1992 & $\begin{array}{l}\text { FIGUEIREDO, Adma } \\
\text { Hamman de }\end{array}$ & $\begin{array}{l}\text { Crédito rural e mudança tecnológica no oeste do } \\
\text { Paraná. }\end{array}$ & $\begin{array}{l}\text { Rev.Brasileira } \\
\text { de Geografia }\end{array}$ \\
\hline 1992 & MÜLLER, Geraldo. & O agrário verde-amarelo hoje e amanhã. & $\begin{array}{l}\text { Rev.Brasileira } \\
\text { de Geografia }\end{array}$ \\
\hline 1994 & $\begin{array}{l}\text { RUAS, Davi Guilherme } \\
\text { Gaspar \& BRAY, } \\
\text { Silvio Carlos. }\end{array}$ & O MERCOSUL e o setor sucroalcooleiro. & $\begin{array}{l}\text { Geografia (Rio } \\
\text { Claro) }\end{array}$ \\
\hline 1995 & BRITO, Maria Socorro. & $\begin{array}{l}\text { Políticas públicas e padrões de uso da terra na } \\
\text { Amazônia Legal. }\end{array}$ & $\begin{array}{l}\text { Rev.Brasileira } \\
\text { de Geografia }\end{array}$ \\
\hline 1996 & $\begin{array}{l}\text { CANDIOTTO, Luciano } \\
\text { Zanetti \& SOARES, } \\
\text { Beatriz Ribeiro }\end{array}$ & Fazenda Boa Vista: uma proposta de ecoturismo. & $\begin{array}{ll}\text { Sociedade } \quad \& \\
\text { Natureza }\end{array}$ \\
\hline 1996 & LISITA, Cyro & $\begin{array}{l}\text { Fronteira e conflito: o processo de ocupação das terras } \\
\text { de Goiás. }\end{array}$ & $\begin{array}{l}\text { Bol. Goiano de } \\
\text { Geografia }\end{array}$ \\
\hline
\end{tabular}




\begin{tabular}{|c|c|c|c|}
\hline 1997 & $\begin{array}{l}\text { SUERTEGARAY, } \\
\text { Dirce Maria Antunes \& } \\
\text { BERTÊ, Ana Maria de } \\
\text { Aveline }\end{array}$ & $\begin{array}{l}\text { Políticas de florestamento em áreas degradadas: areais } \\
\text { do sudoeste do Rio Grande do Sul. }\end{array}$ & Geosul \\
\hline 1997 & $\begin{array}{l}\text { FERNANDES, } \\
\text { Bernardo Mançano }\end{array}$ & A judiciarização da reforma agrária. & Geousp \\
\hline 1998 & $\begin{array}{l}\text { AMARAL, José } \\
\text { Januário de Oliveira }\end{array}$ & $\begin{array}{l}\text { O sentido da colonização agrícola de novas terras: o } \\
\text { exemplo de Rondônia/Brasil. }\end{array}$ & $\begin{array}{l}\text { Bol. Paulista } \\
\text { de Geografia }\end{array}$ \\
\hline 1999 & $\begin{array}{l}\text { ESPÍNDOLA, Carlos } \\
\text { José }\end{array}$ & $\begin{array}{l}\text { Competitividade das agroindústrias do oeste } \\
\text { catarinense no âmbito do MERCOSUL: considerações } \\
\text { preliminares. }\end{array}$ & Geosul \\
\hline 2000 & $\begin{array}{l}\text { ALENTEJANO, Paulo } \\
\text { Roberto. }\end{array}$ & O que há de novo no rural brasileiro? & Terra Livre \\
\hline 2001 & $\begin{array}{lr}\text { CORREAA, } & \text { Josel } \\
\text { Machado; } & \text { CORREAA, } \\
\text { Walquiria } & \text { Krüger; } \\
\text { GERARDI, } & \text { Lucia } \\
\text { Helena de Oliveira }\end{array}$ & $\begin{array}{l}\text { A problemática da definição e da delimitação do } \\
\text { espaço rural e urbano - mudanças no espaço rural e } \\
\text { práticas institucionais: o exemplo da ilha de Santa } \\
\text { Catarina. }\end{array}$ & $\begin{array}{l}\text { Geografia (Rio } \\
\text { Claro) }\end{array}$ \\
\hline 2001 & $\begin{array}{l}\text { HESPANHOL, } \\
\text { Rosângela Aparecida de } \\
\text { Medeiros \& COSTA, } \\
\text { Vera Mariza Henriques } \\
\text { de Miranda. }\end{array}$ & $\begin{array}{l}\text { A agricultura familiar no âmbito do poder local: a } \\
\text { atuação do PRONAF infra-estrutura e serviços } \\
\text { municipais. }\end{array}$ & $\begin{array}{l}\text { Geografia (Rio } \\
\text { Claro) }\end{array}$ \\
\hline 2001 & $\begin{array}{l}\text { SILVA, Clécio } \\
\text { Azevedo da }\end{array}$ & $\begin{array}{l}\text { Integração de políticas rurais no desenvolvimento } \\
\text { regional: a experiência da União Européia. }\end{array}$ & Geosul \\
\hline 2001 & $\begin{array}{l}\text { CORREA, Walquíria } \\
\text { Krüger }\end{array}$ & $\begin{array}{l}\text { As estratégias de ação do grupo USATI- } \\
\text { PORTOBELLO e as transformações no meio rural de } \\
\text { Tijucas (SC). }\end{array}$ & Geosul \\
\hline 2002 & $\begin{array}{l}\text { FABRINI, } \quad \text { João } \\
\text { Edmilson }\end{array}$ & $\begin{array}{l}\text { O projeto do MST de desenvolvimento territorial dos } \\
\text { assentamentos e campesinato. }\end{array}$ & Terra Livre \\
\hline 2002 & $\begin{array}{l}\text { SALAMONI, Giancarla } \\
\& \text { GERARDI, Lúcia } \\
\text { Helena de Oliveira }\end{array}$ & Agroquímica e fumicultura no Rio Grande do Sul. & $\begin{array}{l}\text { Geografia (Rio } \\
\text { Claro) }\end{array}$ \\
\hline 2002 & $\begin{array}{l}\text { DAVID, Cesar De \& } \\
\text { CORREA, Walquíria } \\
\text { Krüger }\end{array}$ & $\begin{array}{l}\text { A política agrária e as transformações na agricultura } \\
\text { brasileira - de } 1960 \text { aos dias atuais. }\end{array}$ & Geosul \\
\hline 2002 & $\begin{array}{l}\text { MEDEIROS, Marlon } \\
\text { Clovis }\end{array}$ & $\begin{array}{l}\text { A reestruturação do complexo agroindustrial do arroz } \\
\text { de Santa Catarina no período } 1990-2000\end{array}$ & Geosul \\
\hline 2002 & $\begin{array}{l}\text { FERNANDES, } \\
\text { Bernardo Mançano \& } \\
\text { PONTE, Karina Furini } \\
\text { da }\end{array}$ & $\begin{array}{l}\text { As vilas rurais do Estado do Paraná e as novas } \\
\text { ruralidades. }\end{array}$ & Terra Livre \\
\hline 2003 & $\begin{array}{l}\text { BERNARDES, Júlia } \\
\text { Adão }\end{array}$ & $\begin{array}{l}\text { Territorialização do capital trabalho e meio ambiente } \\
\text { em Mato Grosso }\end{array}$ & Terra Livre \\
\hline 2003 & CARVALHO, Paulo. & Patrimônio e (re) descoberta dos territórios rurais & $\begin{array}{l}\text { Bol. Goiano de } \\
\text { Geografia }\end{array}$ \\
\hline 2004 & SCOLESE, Eduardo & $\begin{array}{l}\text { De FHC a Lula: manipulações, números, conceitos e } \\
\text { promessas de reforma agrária }\end{array}$ & Terra Livre \\
\hline 2004 & $\begin{array}{ll}\text { SILVA, } & \text { Clécio } \\
\text { Azevedo da } & \\
\end{array}$ & $\begin{array}{l}\text { Da gestão dos recursos hídricos ao desenvolvimento } \\
\text { rural: uma reflexão metodológica }\end{array}$ & $\begin{array}{l}\text { Geografia (Rio } \\
\text { Claro) }\end{array}$ \\
\hline 2004 & \begin{tabular}{lr}
\multicolumn{2}{l}{ CANDIOTTO, Luciano } \\
Zanetti & Pessoa \& \\
CORREAA, Walquíria \\
Kruger
\end{tabular} & $\begin{array}{l}\text { Desenvolvimento } \text { rural } \frac{\text { sustentável: }}{\text { algumas }} \\
\text { considerações sobre o discurso oficial do governo } \\
\text { federal }\end{array}$ & $\begin{array}{l}\text { Geografia (Rio } \\
\text { Claro) }\end{array}$ \\
\hline 2005 & $\begin{array}{l}\text { MITIDIERO JÚNIOR, } \\
\text { Marco Antonio }\end{array}$ & $\begin{array}{l}\text { Os movimentos sociais no campo no Estado de São } \\
\text { Paulo (1995/2001). }\end{array}$ & $\begin{array}{l}\text { Bol. Paulista } \\
\text { de Geografia }\end{array}$ \\
\hline 2006 & OLIVEIRA, Alexandra & A política de contra-reforma agrária do Banco Mundial & Geousp \\
\hline
\end{tabular}




\begin{tabular}{|c|c|c|c|}
\hline & Maria de & no Ceará. & \\
\hline 2006 & $\begin{array}{l}\text { OLIVEIRA, Ariovaldo } \\
\text { Umbelino de }\end{array}$ & A Amazônia e a nova geografia da produção da soja. & Terra Livre \\
\hline 2006 & $\begin{array}{l}\text { FABRINI, } \quad \text { João } \\
\text { Edmilson }\end{array}$ & A escala de luta e resistência camponesa. & Geosul \\
\hline 2007 & $\begin{array}{l}\text { HESPANHOL, } \\
\text { Rosângela Aparecida de } \\
\text { Medeiros. }\end{array}$ & $\begin{array}{l}\text { Perfil das associações de produtores na região de } \\
\text { Presidente Prudente - SP. }\end{array}$ & $\begin{array}{l}\text { Geografia (Rio } \\
\text { Claro) }\end{array}$ \\
\hline 2007 & $\begin{array}{l}\text { HESPANHOL, } \\
\text { Rosângela Aparecida de } \\
\text { Medeiros. }\end{array}$ & As organizações de produtores rurais na França. & Geosul \\
\hline 2007 & $\begin{array}{l}\text { VENCOVSKY, Vitor } \\
\text { Pires \& CASTILLO, } \\
\text { Ricardo }\end{array}$ & $\begin{array}{l}\text { Sistema ferroviário pós-privatização e fluidez } \\
\text { corporativa: o movimento de produtos agrícolas no } \\
\text { território brasileiro. }\end{array}$ & Geousp \\
\hline 2008 & ELESBÃO, Ivo & $\begin{array}{l}\text { A experiência de turismo no espaço rural (TER) em } \\
\text { Portugal. }\end{array}$ & $\begin{array}{l}\text { Geografia (Rio } \\
\text { Claro) }\end{array}$ \\
\hline 2008 & $\begin{array}{l}\text { MESQUITA, Helena } \\
\text { Angélica de }\end{array}$ & Espaço agrário brasileiro: exclusão e inclusão social. & $\begin{array}{l}\text { Bol. Goiano de } \\
\text { Geografia }\end{array}$ \\
\hline 2009 & $\begin{array}{l}\text { ANJOS, Flávio S. dos; } \\
\text { CALDAS, Nádia V; } \\
\text { SILVA, Fernanda N. } \\
\text { da; VALENTE, } \\
\text { Gracieli B; SILVA, } \\
\text { Médelin M. da }\end{array}$ & $\begin{array}{l}\text { Estudo sobre a inadimplência em contratos do } \\
\text { PRONAF no Brasil. }\end{array}$ & $\begin{array}{l}\text { Geografia (Rio } \\
\text { Claro) }\end{array}$ \\
\hline 2009 & $\begin{array}{l}\text { ARANA, Alba Regina } \\
\text { Azevedo } \& \\
\text { BALDASSI, Gláucia }\end{array}$ & $\begin{array}{l}\text { A Reserva Legal no Paraná e os desafios à sua } \\
\text { implantação: um estudo sobre os produtores rurais no } \\
\text { município de Paranacity - PR. }\end{array}$ & Geousp \\
\hline
\end{tabular}
Fonte: Alves (2010).

Nesse sentido, evidenciou-se uma ampliação de estudos ligados a questão política na geografia agrária, seja sob o olhar das políticas públicas, crédito a agricultura, movimentos sociais e reivindicações por terras ou para a reprodução socioeconômica.

\section{Aspectos teórico-metodológicos na geografia humana e agrária brasileira pós 1990}

A partir da década de 1990 considera-se o período da multiplicidade de idéias e concepções na geografia, no qual encontramos uma teia de possibilidades nas pesquisas geográficas. Esta abertura de opiniões se deu com o discurso da renovação da geografia, uma geografia crítica que objetivava desmascarar as diferenças sociespaciais, para tal foi necessário a utilização de diversas abordagens que ressaltasse essa postura.

A pluralidade de visões sobre o espaço reforça a tendência de multiplicidade metodológica existente na geografia atual, questões como a complexidade do espaço, abordagem sistêmica para entender a organização espacial ou entender os processos de 
produção do espaço e das formações socioespaciais estão em voga no discurso epistemológico geográfico.

Para dar conta de tantos vieses, os geógrafos agrários foram procurar em outras ciências o marco teórico para o desenvolvimento das pesquisas, como é o caso de Bernardo Mançano Fernandes (1998) que traz para o debate geográfico as questões interdisciplinares no estudo dos assentamentos rurais da reforma agrária. O autor entende que a pesquisa interdisciplinar entre a filosofia, sociologia, história e literatura podem auxiliar na geografia agrária, no caso o estudo dos assentamentos rurais:

\begin{abstract}
A interdisciplinaridade pode ser construída pela interação que podemos fazer com diversas áreas do conhecimento, através da reflexão filosófica sobre a construção dos conceitos utilizados: sociedade, trabalho, capital, espaço, tempo, território, ambiente, cidade, campo, forma, organização, sujeito, instituição, estrutura, processo, produção, relações sociais, transformação, movimento, classe, cultura etc. (FERNANDES, 1998, p.128).
\end{abstract}

Os conceitos geográficos podem ser interpretados sob outras nuances e prismas filosóficos segundo Fernandes (1998) numa pesquisa geográfica. O autor ainda coloca a questão da interdisciplinaridade como uma barreira a ser superada pelos geógrafos, pois a compartimentação do conhecimento inibe a expansão da ciência:

[...] para a realização de um trabalho interdisciplinar não devemos nos intimidar com o policiamento intensivo que alguns "teóricos" exercem nas fronteiras das áreas do conhecimento. Essa postura em nada contribui para o processo de construção do conhecimento. [...] É fundamental ler trabalhos de outras áreas do conhecimento que possam contribuir para a construção de nossas idéias. (FERNANDES, 1998, p.129).

Essa defesa na multiplicidade de idéias deu o tom das abordagens a partir da década de 1990, com um cenário da globalização e da pós-modernidade da sociedade atual, foi entendido que métodos e teorias únicas não são condizentes com a complexidade das relações humanas e as velocidades das transformações que ocorrem no espaço geográfico.

Nesse sentido, o espaço rural foi altamente alterado com o incremento de tecnologias e a aproximação das relações industriais em boa parte do campo brasileiro, mas esta mudança vem sendo realizada paulatinamente, porém acelerada pós 1990. As temáticas sobre a relação campo e cidade ou urbanização do campo vem ganhando força no discurso geográfico brasileiro, conforme salienta Gláucio Marafon (2009), quando discute sobre a contemporaneidade e os estudos do espaço rural, entendendo a 
diversidade de relações sociespaciais que congregam numa rede complexa de situações, entre elas a relação campo-cidade:

Configuram-se, então, novas relações entre campo e a cidade, com novas qualidades e impressão fortes na paisagem. Além da produção agrícola e da industrialização, temos novas atividades que devem ser identificadas para caracterizar o campo e suas relações com a cidade. (MARAFON, 2009, p.330).

Dentro desse contexto, inúmeras relações sociais ocorrem nesse espaço rural que são processos geradores de conflitos políticos, como é o caso dos movimentos sociais que lutam pela reforma agrária, Marafon (2009) destaca este movimento de complexidade que se forma e transforma no espaço rural, a partir de um elemento que compõe o espaço:

A complexidade do espaço rural é decorrente das profundas transformações ocorridas recentemente, e ela são responsáveis pela subordinação desse espaço aos interesses da cidade. Busca-se, então, compreender essas relações e como os movimentos sociais presentes no campo estabelecem estratégias, nas suas relações com o Estado, para que um maior número de trabalhadores rurais passem a condição de produtores rurais. (MARAFON, 2009, p.330).

Ainda na perspectiva campo-cidade estudada na geografia, João Rua (2005) ao definir o espaço como multidimensional, entende que a relação entre campo e cidade é resultado de múltiplas relações, transescalares, não-hierarquizados num movimento histórico:

Buscando um método multidimensional, pretende-se compreender o espaço (rural), percebendo-o como um espaço híbrido (será explicado mais à frente) pleno de possibilidades e onde experiências inovadoras (algumas com características de resistência) podem ser desenvolvidas. (RUA, 2005, p.47).

Entra em questão, a complexidade do espaço, os avanços tecnológicos, industriais e a força que a cidade exerce na dinâmica rural. Por isso, salienta-se diversas posturas teóricas para tratar desse assunto, Dimas Peixinho et.al. (2003) enfocam o estudo do espaço como um sistema:

Uma instância espacial deve ser vista como um sistema que se hierarquiza na formação do todo, não sendo, portanto, sinônimo de escala, mesmo que a escala seja um recurso para dimensioná-la. Cada instância guarda em si aspectos que particulariza na sua interação com o todo. Nessa perspectiva a escala serve de recurso para focar a dimensão da instância, mas a identidade de cada instância está na função que cada uma exerce dentro do sistema espacial. Portanto, os recortes espaciais que nos ajudam a dimensionar os fenômenos, fundamentais para a nossa análise, não são os constituidores das próprias identidades. (PEIXINHO et.al., 2003, p.85-86). 
A abordagem sistêmica sempre esteve presente nos estudos de geografia agrária, desde a geografia clássica nas questões funcionais da paisagem em relação aos gêneros de vida (por exemplo, os estudos realizados por Pierre Monbeig) passando pela geografia teorética no entendimento da organização do espaço agrário. Neste início de século, a abordagem sistêmica está baseada em diferentes bases teóricas para explicar os fenômenos rurais e urbanos, mas a questão da complexidade do espaço é salientada por Edgar Morin (2005) sendo uma base teórica importante na abordagem sistêmica atual.

Com posição teórica semelhante, Limberger (2006) discute a abordagem sistêmica e a teoria da complexidade como formas de entender a organização espacial na geografia:

Como a Geografia estuda a organização do espaço, e isto engloba entender vários aspectos tanto do geossistema quanto do sistema sócio-econômico e a emergência de sua relação; e como se sabe que tal junção é ainda bastante hipotética (porque se se separa estes "sistemas"; então, se perde a característica sistêmica), enfatiza-se a necessidade de aprofundamento nas discussões e pesquisas em torno da complexidade deste tema. Ou seja, apesar de algumas incompatibilidades entre o conceito e a prática da teoria dos sistemas, não se deve deixar de lado esta abordagem que tende a muito contribuir para o progresso da ciência, inclusive e principalmente, a geográfica. (LIMBERGER, 2006, p.108).

Outro geógrafo que questiona os tipos de enfoques teórico-metodológicos e o objeto de estudo na geografia é Paulo César da Costa Gomes (2005, 2009), para ele a evolução do objeto de estudo da geografia sofreu algumas transformações, mas salienta que toda pesquisa necessita de uma abordagem geográfica, mesmo na atualidade, quando se discute a complexidade e interdisciplinaridade do espaço geográfico. Entretanto, considera que a geografia estuda as inter-relações numa determinada ordem dispersa espacialmente, mas não em sua totalidade, pois é impossível:

Nunca chegaremos a envolver todos os aspectos da miríade dos elementos inter-relacionados na composição dos sistemas espaciais. Seus desenhos, embora possam ser traduzidos em esquemas simplificados para fins de apresentação são o produto de sofisticados processos. (GOMES, 2009, p.26).

Ele reforça a idéia de ordem ou ordenamento espacial, como sendo o enfoque nas pesquisas geográficas, apesar da multiplicidade de temas que podem e devem ser trabalhados pelo geógrafo, deve-se ter com clareza, a questão da ordem espacial:

Há, contudo, sempre uma análise geográfica quando o centro de nossa questão é a ordem espacial, pouco importando o tipo do fenômeno, 
inorgânico, orgânico ou social, até porque essas fronteiras são de difícil delimitação em muitos casos, quando falamos de natureza e de sociedade. (GOMES, 2009, p.27).

Em outro momento Paulo Cesar da Costa Gomes (2005) analisa o discurso marxista na perspectiva do materialismo histórico-dialético e sua utilização na geografia:

\begin{abstract}
O materialismo histórico e dialético é o método que permite a passagem da imagem caótica do real para uma estrutura racional, organizada e operacionalizada em um sistema de pensamento. a primeira etapa deste método é, pois, a busca dos elementos essenciais comuns que estruturam o real [...] A perspectiva marxista encontra no método materialista-histórico o instrumento capaz de projetar a percepção para além do fenomenológico, fazendo sobressair as verdadeiras essências escondidas atrás das aparências. (GOMES, 2005, p.281-282).
\end{abstract}

Essa discussão é posta por Flaviana Nunes (2006) que traz a importância do estudo das relações e processos econômicos para as pesquisas em geografia. Entretanto, a autora deixa claro que estas análises se diferenciam de uma abordagem marxistas e dialética do espaço, no qual o econômico faz parte do entendimento histórico-dialético, sendo muitas vezes o centro da pesquisa. $\mathrm{Na}$ abordagem econômica, não necessariamente, faz-se uma análise histórica e contraditória do capitalismo e das complexidades do espaço geográfico, mas uma introdução das relações sociais na perspectiva econômica.

Nunes (2006) ressalta a predominância de estudos histórico-dialéticos na geografia, no decorrer das décadas de 1980, dando espaço a novas visões metodológicas a partir da década de 1990:

Para compreender esta complexidade, verifica-se, nos últimos anos, a presença de uma multiplicidade de abordagens teórico-metodológicas na geografia, caracterizando um momento diferenciado em relação aos anos 1980, por exemplo, em que havia uma predominância dos referenciais teórico-metodológicos do materialismo histórico e dialético. (NUNES, 2006, p.186-187).

Para Nunes (2006) a estrutura teórico-metodológica da geografia econômica esteve pautada no positivismo, passando pelo marxismo e pelo viés fenomenológico:

As influências teórico-metodológicas deste projeto identificam-se com as próprias formas de entender a geografia após a crise do positivismo: o estruturalismo de caráter relativamente marxista e o humanismo fenomenológico impulsionado pelas filosofias pós-modernas, ambos imbuídos de um sentido crítico em relação ao capitalismo imperante e, 
sobretudo, em relação às suas consequiências em todas as escalas e ordens. (NUNES, 2006, p.189).

A abordagem econômica é muito útil para as análises do espaço geográfico e suas relações e processos:

Para a geografia, o econômico é imprescindível para entender a lógica da organização da sociedade a partir de suas expressões espaciais. Como a economia mudou, dinamizou-se e tornou-se mais presente nas diversas esferas das relações humanas devido à mercadorização de todas as relações, isso se reflete na ordem e vivência espacial, cobrando análises pertinentes. (NUNES, 2006, p.193).

A partir da década de 1990, Nunes (2006) vê uma multiplicidade de concepções teórico-metodológicos na geografia em geral, e também nos estudos econômicos:

[...] a partir do momento em que esse referencial teórico-metodológico (o materialismo histórico e dialético) deixa de ser hegemônico e são introduzidas novas abordagens na geografia, outras dimensões da realidade tais como cultura, gênero, etnia, entre outras também passam a ser valorizadas. (NUNES, 2006, p.195).

Com relação à geografia contemporânea, Dirce Suertegaray (2009) destaca cinco abordagens adotadas do movimento da geografia crítica a outra perspectiva, sendo elas: geografia cultural, geografia neo-marxista, geografia instrumental, geografia fundada no desenvolvimento sustentável e na geografia fundada na natureza externalizada, ou seja, a multiplicidade de concepções ganha relevância nas pesquisas geográfica.

Essas discussões acerca do espaço e das múltiplas abordagens são algumas características da geografia agrária pós 1990, no qual já foi estudada por Darlene Ferreira (2002) até 1995, onde entende que a geografia agrária crítica:

[...] corresponde uma Geografia Agrária preocupada com as questões sociais e econômicas em relação homem-terra e com as relações dos homens do campo entre si e com aqueles das cidades. Essa posição é coerente com uma liberdade de expressão ideológica conquistada após o período ditatorial e com o acirramento dos conflitos sociais numa situação de fechamento de fronteiras à apropriação de terras. É coerente também com preocupações da ordem dos direitos humanos e do uso (e abuso) dos recursos naturais, num mundo que se tecnifica e imediatiza (FERREIRA, 2002, p.340).

A autora destaca o aumento da análise sociológica nos estudos geográficos do rural, salientando uma diminuição das abordagens espaciais "a incorporação de 
conceitos e teorias sociológicas e econômicas marcou presença nos estudos da década de 1990. A questão espacial foi suplantada pelo social, e a referência a grupos, sujeitos, classes sociais, entidades, lutas, tornou-se evidente" (FERREIRA, 2002, p.333).

Após a publicação de Ferreira (2002) até 2009, houve poucos levantamentos bibliográficos densos sobre o tema metodológico e historiográfico na geografia agrária, no qual fizesse algumas constatações do cenário atual e apontamentos para o futuro. Nesse sentido, este artigo ressalta a pesquisa de Alves (2010) onde visualiza os principais aspectos metodológicos na geografia agrária brasileira fundamentada na produção bibliográfica presente nos periódicos científicos selecionados.

\section{Principais abordagens metodológicas na geografia agrária}

A definição das abordagens metodológicas seguiu alguns pressupostos classificatórios, na tentativa de sistematização do material consultado. Tendo em vista os grandes métodos da ciência, indutivo, dedutivo, dialético e fenomenológico, nos esforçamos para não agrupar os artigos pesquisados neste rol de métodos, mas sim em expandir o horizonte classificatório, pois muitos textos não deixavam claros as suas bases teórico-metodológicas, bem como uma junção de idéias desconexas com o método aparentemente pré-julgado.

Nesse sentido, criaram-se dezoito abordagens metodológicas ${ }^{1}$ após as análises realizadas, com intuito de percorrer o trajeto da geografia agrária contemplando o máximo de concepções. A classificação dos artigos primou para a sua inserção em uma abordagem, entretanto, muitos artigos apresentavam múltiplos aspectos quanto sua abordagem, assim não se deteve a apenas uma. Neste artigo, enfocaremos a abordagem política como um sub-campo da geografia conforme lembra Corrêa (2010), salientando sua utilização pós 1990.

\section{Abordagem política nas questões agrárias}

Neste tipo de abordagem os trabalhos desenvolvidos se preocupam com as questões relacionadas com o poder e influência dos diferentes níveis de governos 
(municipal, estadual ou nacional) nas questões territoriais do campo, sejam para as políticas de abastecimento, políticas fundiárias ou políticas de preservação ambiental.

Retomando os clássicos da geografia, Frederic Ratzel introduziu a discussão do Estado na organização territorial e suas influências na dinâmica da população. Entretanto, na geografia agrária, esta abordagem se desenvolverá amplamente na década de 1980, com os trabalhos da corrente crítica, devido à conjugação de fatores que interferem nas relações sociais, entre esses fatores está à atuação do Estado e das políticas públicas na organização do espaço agrário.

A relação de poder é marcante nessas abordagens, e a categoria território ganha espaço nas bases conceituais das pesquisas agrárias, por se referir a um espaço intrínseco, delimitado por relações de poder ou identidade. Cita-se os referencias de Claude Raffestin (1993), Rogério Haesbaert (2004), Marcelo Souza (2003) entre outros geógrafos que analisam a questão territorial sobre a perspectiva do poder na abordagem política.

Convém destacar, os estudos sobre políticas públicas para os agricultores, crédito, políticas fundiárias, políticas ambientais, ou seja, os impactos de diferentes políticas para o desenvolvimento do espaço agrário e como o geógrafo interpreta essa temática sob a prisma de sua ciência e na conjugação interdisciplinar.

\title{
Produção bibliográfica na década de 1990
}

Na década de 1990, salienta-se a grande preocupação dos geógrafos em discutir temas relacionados às questões políticas que interferem diretamente na organização agrária, seja para o aumento da produção agrícola ou para as questões fundiárias. O trabalho de Kohlhepp (1991) mostra a evolução dos sistemas agropecuários no Paraná desde a década de 1960, enfatizando as decisões políticas nestas mudanças estruturais:

\begin{abstract}
A exposição a seguir tem por objetivo a análise das sucessões de uso da terra no norte do Paraná desde os anos 60, assim como a pesquisa de suas causas e consequiências. No centro do interesse encontram-se as transformações de estruturas agroespaciais da monocultura do café em uma modernização agropecuária baseada em uma nova política agrária estatal. (KOHLHEPP, 1991, p.79).
\end{abstract}

\footnotetext{
${ }^{1}$ Para conhecer todas as abordagens empregadas no estudo da história da geografia agrária brasileira ver em Alves (2010).
} 
Esse processo de modernização no campo expandiu a fronteira agrícola atingindo novas áreas produtivas, como o Centro-Oeste e a Amazônia, sobre isso Machado (1992) analisa o processo histórico de ocupação da Amazônia, a fronteira agrícola, e as políticas governamentais de ocupação e colonização do território amazônico:

[...] o problema mais grave na fronteira agrícola amazônica é a reprodução da mesma estrutura econômica socialmente injusta que gera a organização do conjunto do território brasileiro, reforçado pelo domínio do transitório, fato comum as áreas de ocupação recente, o que permite caracterizá-la como área de instabilidade e incerteza, aumentando as pressões sobre a população além do limiar dos riscos inerentes a uma ocupação pioneira. (MACHADO, 1992, p.54).

Na mesma linha, Maria Socorro Brito (1995) discute as políticas adotadas pelos órgãos governamentais, a partir da década de 1960, para ocupação do uso de terras na Amazônia Legal, para fins agropecuários e de povoamento:

O fato de essa região ter se constituído em área estratégica do planejamento oficial, no contexto de expansão da fronteira de recursos do País, favoreceu mudança de seu papel de área extrativista, para transformá-la em espaço aberto ao capital, onde a incorporação de terras ao processo produtivo se deu, não só, pela implantação de grandes projetos agropecuários, como pela colonização dirigida e pelo povoamento espontâneo. (BRITO, 1995, p.74).

Ainda sobre a região amazônica, José Amaral (1998) apresenta os aspectos políticos e sociais da colonização realizada em Rondônia:

A dimensão espacial envolve trajetórias sociais de regiões distintas, seja no sentido rural/rural, seja no sentido rural/urbano. Estas migrações estão recheadas de conteúdos particulares, porém existe uma reciprocidade nas relações. O colono passa simultaneamente por dois vieses: o da dessocialização em sua região de origem, e o da ressocialização nas novas terras. (AMARAL, 1998, p.132).

Para Amaral (1998) o Estado foi decisivo para aumentar as contradições sociais e acirrar os conflitos fundiários, nos projetos de colonização em Rondônia:

O papel do Estado é ressaltado como "maestro" dos conflitos sociais e dos processos sociais emergentes. Ele exerce funções normativas na acumulação e na legitimação e age como "fio condutor" dos processos sociais. Intervém diretamente em várias escalas espaciais, estimulando diversos fluxos, aliviando tensões sociais localizadas e combatendo frontalmente outros movimentos. (AMARAL, 1998, p.135). 


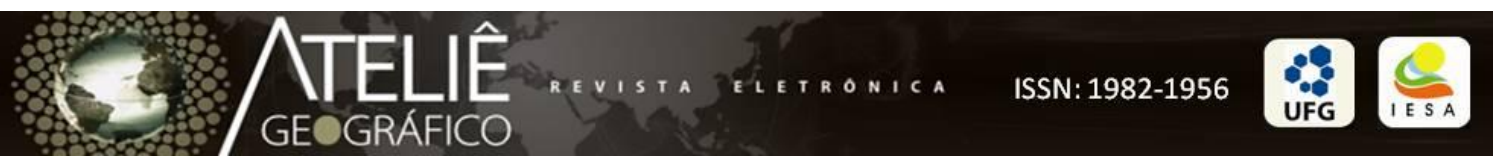

A respeito das decisões políticas para o desenvolvimento rural, Maria Vargas

(1992) mostra as políticas de desenvolvimento adotadas para solucionar o problema das secas no nordeste, a partir da década de 1960:

Na produção do espaço e reprodução de seu espaço, o "Polígono das Secas" é definido territorialmente como área sujeita a secas periódicas, politicamente como área problema e economicamente como área carente de modernização, de transformação de sua base produtiva. [...] A intenção do Estado em converter o sertão em terras agricultáveis com base no desenvolvimento de uma agricultura moderna, realizada por agricultores proprietários e não por agricultores posseiros e arrendatários, passa pela atuação de agentes nos níveis federal, estadual, e principalmente local, geralmente atravessados pelo jogo das forças sociais nos seus diversos níveis. (VARGAS, 1992, p.53-54).

Já o trabalho de Candiotto e Soares (1996) discute as políticas públicas voltadas para a prática do turismo em área rurais, em especial o ecoturismo. Os autores descrevem os fatores naturais e ambientais positivos numa fazenda no município de Prata-MG:

\begin{abstract}
O conhecimento dos aspectos físicos da área pesquisada para a atividade turística é fundamental para se determinar com clareza o tipo de uso e manejo do local, ou seja, como pode ser explorada e o que deve ser preservado, o tipo de atividade econômica a ser desenvolvida, com o intuito de minimizar os impactos negativos, pois é necessário para manter a qualidade dos atrativos à visitação de turistas, principalmente no ecoturismo e turismo rural, que dependem da preservação da natureza para seu desenvolvimento e sustentabilidade. (CANDIOTTO \& SOARES, 1996, p.65-66).
\end{abstract}

Cyro Lisita (1996) mostra a evolução da estrutura agrária em Goiás e a ligação com as políticas vigentes no país, desde a Lei de Terras de 1850 passando pelo Estatuto da Terra de 1964, até as políticas recentes da década de 1980.

A questão fundiária é tema, de grande parte dos trabalhos sob esta abordagem na geografia agrária, e entre esses autores, destaca-se Bernardo Mançano Fernandes, que através de estudos empíricos com o MST, desenvolve teorias sobre a territorialização dos assentados, sob o viés do poder, identidade e constituição política do movimento. A respeito disso, Fernandes (1997) analisa as políticas e formas jurídicas que são adotadas na questão agrária em relação ao Movimento dos Trabalhadores Rurais Sem-Terra pela luta da terra:

Iniciamos uma reflexão a respeito de uma questão que vem se destacando nos conflitos fundiários: a judiciarização da reforma agrária. Discutimos as diferentes respostas que o Poder Judiciário tem dado às ações do Movimento dos Trabalhadores Rurais Sem-Terra (MST), com o objetivo de contribuir 
com o debate a respeito da questão da reforma agrária. (FERNANDES, 1997, p.34).

Em outra linha de análise, Paulo Alentejano (2000) discute as políticas governamentais e textos acadêmicos com relação ao conceito do "Novo Rural" para o campo brasileiro:

O objetivo deste texto é analisar os principais processos de transformação em curso no agro brasileiro, de modo a identificar as novidades $\mathrm{e}$ as permanências, permitindo uma compreensão do que há de novo neste mundo rural.

Para isto, analisaremos alguns textos que buscam explicar as transformações em curso na realidade agrária brasileira, assim como documentos governamentais e posicionamentos de organizações não-governamentais (ONGs) e de movimentos sociais a respeito da questão. (ALENTEJANO, 2000, p.87).

Estes estudos que enfocam os aspectos políticos da questão agrária, muitas vezes estão associados aos aspectos econômicos dessas políticas, a respeito dessas abordagem Geraldo Müller (1992) apresenta as conseqüências da mudança de padrão tecnológico e produtivo na agricultura na década de 1980, numa abordagem econômicapolítica:

O subdesenvolvimento no Brasil não radica em sua agricultura, em sua agroindústria e em sua indústria, comércio e serviços, mesmo que nestes setores, como em outros de nossa vida nacional, tenhamos que superar defasagens tecnológicas, organizacionais e institucionais. Nosso subdesenvolvimento se funda na inexistência de instituições capazes de permitir a transferência de fundos intersetoriais, em relação aos quais se considere os serviços sociais como condição indispensável para assegurar o crescimento econômico e uma coesão social dinâmica. (MÜLLER, 1992, p.46).

Espíndola (1999) analisa as possibilidades de integração das agroindústrias do oeste catarinense no mercado sul-americano, em especial, os países componentes do MERCOSUL:

[...] os grupos agroindustriais do oeste catarinense, principalmente, Sadia, define suas estratégias em função de uma gama de produtos, chegando a uma agressiva política de penetração nos mercados mais dinâmicos. Com isso, define suas estratégias nos diferentes espaços regionais e internacionais. Trata-se, portanto, de uma relação intrínseca entre estruturas de sustentação produtiva e estratégias dinâmicas empresariais. (ESPÍNDOLA, 1999, p.136137).

Temas políticos ganham força após 1980 na geografia como um todo, e na geografia agrária não poderia ser diferente, a luta pela reforma agrária, melhor 
distribuição dos recursos financeiros com os agricultores são questões em debate na geografia. O que deve ser indispensável de se ressaltar nessa abordagem, é o foco na questão espacial, como as políticas públicas, em especial, interferem na organização do espaço agrário.

\section{Produção bibliográfica no início do século XXI}

Indiscutivelmente, a preocupação da geografia em expor os problemas e demandas de políticas públicas para a organização do espaço agrário, ganhou relevo neste início de século. Como um instrumento que pode interferir decisivamente social e economicamente para os agricultores, as questões políticas denotam o caráter crítico e preocupado com o social que o geógrafo incorporou. É conveniente exaltar essa preocupação, obviamente, quando associada aos princípios e pressupostos da ciência geográfica.

Tratando das políticas direcionadas a agricultura familiar, Flavio dos Anjos et.al. (2009) discute sobre a política de crédito rural do PRONAF, e a inadimplência nos contratos, revelando as dificuldades encontradas por uma parcela de agricultores. Em outro estudo, Rosângela Hespanhol e Vera Costa (2001) discorrem sobre a importância de ordem político-econômico do PRONAF e dos Conselhos Locais na agricultura familiar, situando o caso dos municípios de Alfredo Marcondes e Álvares Machado em São Paulo:

\footnotetext{
Nesse contexto, deve-se reconhecer, ainda que de forma preliminar, a importância que o PRONAF Infra-Estrutura e Serviços tem assumido em alguns municípios que foram contemplados com os recursos dessa linha de financiamento, criando condições econômicas e políticas para que as associações de produtores familiares intervenham na realidade local, firmando-se como entidades aglutinadoras e representativas dos agricultores nas demais instâncias do poder local (prefeituras municipais, Conselhos de Desenvolvimento Rural, Casas da Agricultura, etc.). (HESPANHOL \& COSTA, 2001, p.88-89).
}

As estratégias de reprodução social e econômica dos agricultores familiares em Urubici - SC foram tratadas por Walquíia Corrêa (2001) que apontou as políticas de crédito e de assistência técnica como alternativa para a cultura da maça. Para alguns autores, essas políticas estão diretamente associadas ao desenvolvimento rural e, inclusive, desenvolvimento sustentável, conforme o estudo de Luciano Candiotto e 
Walquíria Corrêa (2004), onde apresentam algumas atribuições do Governo Federal referente ao desenvolvimento rural sustentável frente à agricultura familiar:

Através dos documentos que analisamos, bem como da comparação entre o discurso do governo sobre o desenvolvimento sustentável e de suas ações efetivas - que praticamente não ocorreram, e muitas das que ocorreram nada têm a ver com a sustentabilidade, tanto no governo FHC, como no governo Lula até então - podemos afirmar que o Brasil está buscando única e exclusivamente, o caminho do desenvolvimento sustentado. (CANDIOTTO \& CORRÊA, 2004, p.278).

$\mathrm{Na}$ linha de pesquisa sobre os assentamentos rurais, João Fabrini (2002) aborda o contexto político e econômico do MST na formação e construção do território camponês:

No processo de construção do território, verifica-se que as cooperativas despontaram como forma de participação dos assentados enquanto sujeito político. Entretanto, é a partir da inclusão econômica e produtiva que as cooperativas representam, que o MST entende que os assentados vão se tornar sujeitos políticos. E ainda, é como se a participação política exigisse o desenvolvimento de forças produtivas para existir. (FABRINI, 2002, p.91).

Numa escala regional das políticas voltadas para a agricultura, Clécio Silva (2001) analisa as políticas de desenvolvimento rural e agrícola européias, como a Política Agrícola Comum (PAC) e suas contribuições para o desenvolvimento regional.

É certo que a experiência européia de integração de políticas rurais no desenvolvimento regional é muito particular no universo capitalista e não pode apresentar pistas diretas para a investigação de um processo de integração periférica como, por exemplo, o bloco MERCOSUL. Contudo, pode-se extrair alguns importantes aspectos metodológicos. (SILVA, 2001, p.70).

Outro trabalho que segue a abordagem política é desenvolvido por Clécio Silva (2004), quando coloca as possibilidades da gestão de bacias hidrográficas e dos recursos hídricos como política de desenvolvimento rural.

Fazendo um levantamento histórico das políticas aplicadas no campo brasileiro desde 1960 a te o início do século XXI, Cesar de David e Walquíria Corrêa (2002) discutem a respeito deste tema:

O papel do Estado, como gestor de projetos, deve ser enfatizado quando se analisam os processos econômico-sociais no espaço agrário, efetivados através de políticas públicas: as agrárias, que envolvem os projetos de colonização e reforma agrária; e as agrícolas, voltadas ao crédito e aos preços mínimos. (DAVID \& CORRÊA, 2002, p.24). 
O cenário do campo brasileiro da década de 1960 pouco se alterou até o início do século XXI, quanto às desigualdades socioeconômicas, conforme o estudo desenvolvido por Helena Mesquita (2008), que expressa essa desigualdade às políticas governamentais:

O modelo de desenvolvimento do país, especialmente o que se refere ao campo, como no processo de modernização da agricultura, é gerador de concentração e exclusão. A estratégia da modernização adotada foi claramente conservadora, e teve como objetivo básico o aumento da produção e da produtividade da terra e do trabalho. A forma foi uma renovação tecnológica com utilização de equipamentos, insumos, técnicas e métodos modernos, e o emprego mínimo de mão-de-obra, com tendência à especialização da mesma. (MESQUITA, 2008, p.135).

Uma crítica pontual as políticas nos governos FHC e Lula foram discutidas por Eduardo Scolese (2004), no qual, através de uma análise de textos de jornais expôs os números e informações sobre a reforma agrária do governo FHC e o início do governo Lula:

[...] a exposição, narrada de forma jornalística, sobre os números da reforma agrária nos governos Fernando Henrique Cardoso (1995-2002) e Luiz Inácio Lula da Silva (2003 e início de 2004). A pressão dos movimentos sociais e dos partidos de oposição a tais governos tem ou tiveram como base as metas de assentamentos, deixando a qualidade dos projetos em segundo plano. (SCOLESE, 2004, p.123).

No mesmo tom de crítica, Ariovaldo Oliveira (2006) explora as questões políticas da ocupação do território amazônico, analisando o crescimento da produção de soja e a luta pela reforma agrária:

Este artigo pretende continuar contribuindo para a discussão sobre o significado da expansão da soja sobre a floresta amazônica, seu estágio e seus cenários futuros. Mas esta discussão não se completa se as questões relativas à grilagem das terras públicas e devolutas não estivessem também na ordem do dia. Por isso, a questão da expansão da soja está relacionada ao movimento dos grileiros de terra sobre a Amazônia. (OLIVEIRA, 2006, p.15).

Em uma perspectiva desenvolvimentista das lavouras modernas, Vencovsky e Castillo (2007) discutem as políticas do sistema ferroviário brasileiro e seu uso para escoamento da produção agrícola no cerrado brasileiro, sob a égide do referencial de Milton Santos, acerca do meio técnico-científico-informacional:

Para o escoamento da produção de soja dos novos fronts agrícolas, governos e empresas estão fortalecendo ainda mais os corredores de transporte e exportação. Estes são considerados como o espaço dos fluxos que não 
abrangem todo o espaço, ou seja, são subsistemas formados por pontos, linhas e manchas (SANTOS, 2002, p. 296) ${ }^{2}$ e utilizados por poucos. (VENCOVSKY \& CASTILLO, 2007, p.129).

Essa modernização no campo, ocorrida pelas políticas que se iniciaram na década de 1960, transformaram a forma do espaço rural, acrescendo novos elementos para este espaço, antes intrínsecos do espaço urbano. Nesse sentido, Josel Corrêa, Walquiria Corrêa e Lucia Gerardi (2001) apresentam algumas definições sobre o espaço rural e urbano de acordo com as leis ordinárias, como a Constituição Federal e o Estatuto da Terra. Este tema entrará com intensidade na geografia agrária, sobre a ruralidade, multifuncionalidade do espaço e pluriatividade dos agricultores, assim, a respeito da multifuncionalidade do espaço rural Ivo Elesbão (2008) discorre sobre o processo de produção do turismo rural em Portugal, na perspectiva política, já no artigo de Bernardo Fernandes e Karina Ponte (2002) exploram as questões políticas da questão da ruralidade e o "Novo Rural" no estudo das vilas rurais no Estado do Paraná:

[...] pretendemos analisar os significados e os componentes do Programa Vilas Rurais do Estado do Paraná. Para isso, partiremos de questionamentos sobre o método de análise do "novo rural" e buscaremos repensar novos métodos que permitam entender as novas ruralidades que estão se configurando. Sendo assim, contribuirá para uma reflexão dos sentidos assumidos pelas políticas públicas no Brasil e principalmente das Vilas Rurais, o que vem no sentido de viabilizar certos interesses das classes dominantes. (FERNANDES \& PONTE, 2002, p.113).

Assinalamos esta tendência na geografia agrária neste início de século, a inquietação dos pesquisadores com as políticas governamentais que subsidiam aos sistemas agropecuários no Brasil, sejam eles para a reorganização da estrutura fundiária, no caso dos assentamentos rurais ou para a expansão das atividades empresariais, como é o caso da soja. Entre esses dois pólos, começa-se a debater novas políticas de desenvolvimento para o campo, que não seja eminentemente agrícola, neste caso, as políticas direcionadas a pluriatividade.

\section{Conclusões}

Destaca-se o crescimento de questões políticas tratadas pela geografia agrária neste início de século, o geógrafo tende a desenvolver pesquisas que entendam a

\footnotetext{
${ }^{2}$ SANTOS, Milton. A natureza do espaço. São Paulo: Edusp, 2002.
} 
dinâmica espacial e como as políticas podem interferir positivo e negativamente nessa distribuição e organização do espaço, como é o caso das políticas fundiárias e de reforma agrária. Dessa forma, as atividades econômicas são peças importantes neste tipo de análise e quase sempre estão associadas à abordagem política.

Tornam-se necessários estudos teóricos que apontem para o cenário futuro da geografia agrária diante da complexidade do espaço e das transformações que ocorrem em velocidades, cada vez mais rápidas e dinâmicas, interligando vários elementos que compõem a organização espacial. Assim, neste início de século o debate está em descobrir metodologias que contemplam essa diversidade de relações e processos, numa perspectiva geográfica, mas não isolada das outras ciências.

Entra com força o debate da interdisciplinaridade, pois muitos cientistas não consideram suficiente uma base teórica e prática para explicar os fenômenos da sociedade. Na geografia o emprego de referenciais de outras áreas do conhecimento sempre esteve presente, seja a Geografia Clássica próxima das Ciências Naturais, a Geografia Teorética próxima das Ciências Exatas. Todavia, o enfoque geográfico (relação sociedade x natureza e a organização do espaço) esteve presente nas análises, a grande preocupação se refere à geograficidade dos trabalhos interdisciplinares, ou seja, o geógrafo não deve abandonar as teorias, categorias e conceitos geográficos que denotam o status de Ciência para a Geografia.

Desta forma, adotamos uma postura coerente com as necessidades de cada pesquisa, mas nunca deixando o enfoque geográfico em segundo plano, onde a questão espacial deve ser base de qualquer investigação geográfica. A postura da interdisciplinaridade é válida para a ciência, pois aumenta o rol de opções na tentativa de explicar um fenômeno. Entretanto, isso deve ocorrer na medida em que o pesquisador tenha conhecimento e base de sua ciência de origem, para posteriormente extrair novas ideias e conteúdos em outra ciência aplicando no estudo em questão.

\section{Referências}

ALENTEJANO, Paulo Roberto R. O que há de novo no rural brasileiro? p.87-112. Terra Livre. n. 15, 2000.

ALVES, Flamarion Dutra. Trajetória teórico-metodológica da geografia agrária brasileira: a produção em periódicos científicos de 1939-2009. Tese de Doutorado 
(Geografia - Organização do Espaço). Rio Claro: Universidade Estadual Paulista, 2010. $350 \mathrm{p}$.

AMARAL, José Januário de Oliveira. O sentido da colonização agrícola de novas terras: o exemplo de Rondônia/Brasil. p.131-142. Boletim Paulista de Geografia. v.71, dez. 1998.

ANJOS, Flávio S. dos; CALDAS, Nádia V; SILVA, Fernanda N. da; VALENTE, Gracieli B; SILVA, Médelin M. da. Estudo sobre a inadimplência em contratos do PRONAF no Brasil. p.473-486. Geografia. Rio Claro, v.34, n.3, 2009.

BRITO, Maria Socorro. Políticas públicas e padrões de uso da terra na Amazônia Legal. p.73-94. Revista Brasileira de Geografia. v.57, n.3, 1995.

CANDIOTTO, Luciano Zanetti \& SOARES, Beatriz Ribeiro. Fazenda Boa Vista: uma proposta de ecoturismo. p.63-70. Sociedade \& Natureza. v.8, n.16, 1996.

CANDIOTTO, Luciano Zanetti Pessoa \& CORRÊA, Walquíria Kruger. Desenvolvimento rural sustentável: algumas considerações sobre o discurso oficial do governo federal. p.265-280. Geografia. Rio Claro, v.29, n.2, 2004.

CORRÊA, Roberto Lobato. A trajetória da geografia brasileira: uma breve interpretação. p.63-69. Terra Livre. v.1, n.34, 2010.

CORRÊA, Walquíria Krüger. A agricultura familiar e a nova modalidade de integração ao mercado: o caso da cultura da maça. p.113-130. Geografia. Rio Claro, v.26, n.3, 2001.

CORRÊA, Josel Machado; CORRÊA, Walquiria Krüger; GERARDI, Lucia Helena de Oliveira. A problemática da definição e da delimitação do espaço rural e urbano mudanças no espaço rural e práticas institucionais: o exemplo da ilha de Santa Catarina. p.37-58. Geografia. Rio Claro, v.26, n.1, 2001.

DAVID, Cesar De \& CORRÊA, Walquíria Krüger. A política agrária e as transformações na agricultura brasileira - de 1960 aos dias atuais. p.23-43. Geosul. v.17, n.33, 2002.

ELESBÃO, Ivo. A experiência de turismo no espaço rural (TER) em Portugal. p.553568. Geografia. Rio Claro, v.33, n.3, 2008.

ESPÍNDOLA, Carlos José. Competitividade das agroindústrias do oeste catarinense no âmbito do MERCOSUL: considerações preliminares. p.125-138. Geosul. v.14, n.28, 1999.

FABRINI, João Edmilson. O projeto do MST de desenvolvimento territorial dos assentamentos e campesinato. p.75-94. Terra Livre. n.19, 2002.

FERNANDES, Bernardo Mançano. A judiciarização da reforma agrária. p.35-39. Geousp. v.1, 1997.

Questões teórico-metodológicas da pesquisa geográfica em assentamentos da reforma agrária. p.83-129. Boletim Paulista de Geografia. v.75, dez. 1998.

FERNANDES, Bernardo Mançano \& PONTE, Karina Furini da. As vilas rurais do Estado do Paraná e as novas ruralidades. p.113-126. Terra Livre. n.19, 2002. 
FERREIRA, Darlene Aparecida de Oliveira. Mundo Rural e Geografia. Geografia agrária no Brasil: 1930-1990. São Paulo: Editora UNESP, 2002.

GOMES, Paulo Cesar da Costa. Geografia e modernidade. 5.ed. Rio de Janeiro: Bertrand Brasil, 2005.

Um lugar para a geografia: contra o simples, o banal e o doutrinário. p.1330. In: MENDONÇA, Francisco de Assis; LOWEN-SAHR, Cicilian Luiza; SILVA, Márcia da. (Org.) Espaço e Tempo: complexidade e desafios do pensar e do fazer geográfico. Curitiba: ADEMADAN, 2009.

HAESBAERT, Rogério. O Mito da Desterritorialização: do "fim dos territórios" à multiterritorialidade. Rio de Janeiro: Bertrand Brasil, 2004.

HESPANHOL, Rosângela Aparecida de Medeiros \& COSTA, Vera Mariza Henriques de Miranda. A agricultura familiar no âmbito do poder local: a atuação do PRONAF infra-estrutura e serviços municipais. p.69-90. Geografia. Rio Claro, v.26, n.2, 2001.

KOHLHEPP, Gerd. Mudanças estruturais na agropecuária e mobilidade da produção rural no norte do Paraná - Brasil. p.79-94. Revista Brasileira de Geografia. v.53, n.2, 1991.

LIMBERGER, Leila. Abordagem sistêmica e complexidade na geografia. p.95-109. Geografia. Londrina, v.15, n.2, 2006.

LISITA, Cyro. Fronteira e conflito: o processo de ocupação das terras de Goiás. p.2940. Boletim Goiano de Geografia. v.16, n.1, 1996.

MACHADO, Lia. A fronteira agrícola na Amazônia brasileira. p.27-56. Revista Brasileira de Geografia. v.54, n.2, 1992

MARAFON, Gláucio. Permanências e mudanças no campo: uma leitura sobre as transformações recentes no espaço rural fluminense. p.329-347. In: MENDONÇA, Francisco de Assis; LOWEN-SAHR, Cicilian Luiza; SILVA, Márcia da. (Org.) Espaço e Tempo: complexidade e desafios do pensar e do fazer geográfico. Curitiba: ADEMADAN, 2009.

MESQUITA, Helena Angélica de. Espaço agrário brasileiro: exclusão e inclusão social. p.127-142. Boletim Goiano de Geografia. v.28, n.1, 2008.

MORIN, Edgar. O método 1: a natureza da natureza. 2.ed. Tradução Ilana Heineberg. Porto Alegre: Sulina, 2005.

MÜLLER, Geraldo. O agrário verde-amarelo hoje e amanhã. p.29-48. Revista Brasileira de Geografia. v.54, n.4, 1992

NUNES, Flaviana Gasparotti. A importância do econômico na geografia atualmente: algumas questões para o debate. p.185-196. Terra Livre. v.2, n.27, 2006.

OLIVEIRA, Ariovaldo Umbelino de. A Amazônia e a nova geografia da produção da soja. p.13-43. Terra Livre. v.1, n.26, 2006.

PEIXINHO, Dimas Moraes; BERNARDES, Júlia Adão; SCOPEL, Iraci; MELO, Nágela Aparecida de. A reestruturação espacial e a interação entre o local e o global: o exemplo da soja. p.83-112. Boletim Goiano de Geografia. v.23, n.1, 2003. 
RAFFESTIN, Claude. Por Uma Geografia do Poder. (Tradução Maria Cecília França) São Paulo: Editora Ática, 1993.

RUA, João. A resignificação do rural e as relações cidade-campo: uma contribuição geográfica. p.45-66. In: Revista da ANPEGE. v.2, 2005.

SCOLESE, Eduardo. De FHC a Lula: manipulações, números, conceitos e promessas de reforma agrária. p.123-138. Terra Livre. v.2, n.23, 2004.

SILVA, Clécio Azevedo da. Integração de políticas rurais no desenvolvimento regional: a experiência da União Européia. p.51-72.Geosul. v.16, n.32, 2001.

Da gestão dos recursos hídricos ao desenvolvimento rural: uma reflexão metodológica. p.101-110. Geografia. Rio Claro, v.29, n.1, 2004.

SOUZA, Marcelo J. L.. O território: sobre espaço e poder, autonomia e desenvolvimento. p. 77-116. In: CASTRO, I. E.; GOMES, P. C. da C.; CORRÊA, R. L. (Orgs.) Geografia: conceitos e temas. 6.ed. Rio de Janeiro: Bertrand Brasil, 2003.

SUERTEGARAY, Dirce Maria Antunes. Geografia contemporânea movimento e crítica. p.107-120. In: MENDONÇA, Francisco de Assis; LOWEN-SAHR, Cicilian Luiza; SILVA, Márcia da. (Org.) Espaço e Tempo: complexidade e desafios do pensar e do fazer geográfico. Curitiba: ADEMADAN, 2009.

VARGAS, Maria Augusta Mundin. A natureza sertaneja das políticas de desenvolvimento: sertão sergipano do São Francisco. p.27-60. Boletim Paulista de Geografia. v.69, 1992.

VENCOVSKY, Vitor Pires \& CASTILLO, Ricardo. Sistema ferroviário pósprivatização e fluidez corporativa: o movimento de produtos agrícolas no território brasileiro. p.119-134. Geousp. n.21, 2007.

Recebido para publicação em fevereiro de 2011.

Aprovado para publicação em julho de 2011. 